\title{
Synthesis of A and X Zeolites from Non Magnetic Ash of Rice Husks Through the Hydrothermal Process in the Alkaline Bases Condition
}

\author{
Iis Siti Jahro ${ }^{1}$, Asep Wahyu Nugraha ${ }^{2}$ and Nurfajriani ${ }^{3}$ \\ \{jahrostiis@gmail.com ${ }^{1}$ \} \\ Chemistry Department, Medan State University, William Iskandar Street, Medan, Indonesia ${ }^{1,2,3}$
}

\begin{abstract}
In the general, rice mills produce rice, husks and brand around 72, 20 and $8 \%$ respectively. The burning of rice husks produce ash around $18 \%$. Ash of rice husks contain silica which is zeolite-forming mineral around $88 \%$. The purification ash of rice husks was conducted through a magnetic separation process using a bar magnet in water. Magnetic separation process produce $92.36 \%$ non magnetic ash of rice husks and 5.64\% impurities magnetic. The synthesis of zeolite from non magnetic ash of rice husks through hydrothermal process in an alkaline condition. It was carried out by starting process of forming sodium silicate and aluminate compounds through the reaction of non magnetic ash of rice husks with $\mathrm{Al}_{2} \mathrm{O}_{3}$ and $\mathrm{NaOH}$ in water accompanied by stirring at $600 \mathrm{rpm}$ in the room temperature for 10 hours. Then the results of reaction was refluxed at $70^{\circ} \mathrm{C}$ for 3 hours so that a mixture of gel was produced. After being stored for 12 hours or more at room temperature, the mixture of gel was refluxed again at $100^{\circ} \mathrm{C}$ for 7 hoursuntil A-zeolite was produced. However, the production of X-zeolite which the mixture of gel was refluxed at $120^{\circ} \mathrm{C}$ for 8 hours. The results of FT-IR and XRD charaterization showed that the A-zeolite has infrared absorption bands in the wave number region of $426.26,603.24,1000 \mathrm{~cm}-1$ and diffraction peaks at $2 \theta$ angles of 12.42 , $17.65,21.63,28.70$ and 33.51 degrees. Whereas the X-zeolite showed infrared absorption bands in the wave number regions of $440.70,606.44,745.14,1007.88 \mathrm{~cm}-1$ and diffraction peaks at $2 \theta$ angles of $12.34,17.51,21.53,27.90,28.50$ and 33.22 degrees.
\end{abstract}

Keywords: Ash of rice husks, zeolite, synthesis, characterization.

\section{Introduction}

Environmental pollution is a common problem because it concerns health and safety life of humans and living things. The burning of rice husks can produce toxic gases of $\mathrm{CO}$ and $\mathrm{CO} 2$ which cause a depletion or leakage of the ozone layer. The results of chemical composition analysis showed that ash of rice husks contained around $96.26-97.10 \%$ of silica ( $\mathrm{SiO} 2)$.It was very potential as a material to synthesize zeolite (Usman at al, 2014). Zeolite synthesis includes the stages of gel formation and crystallization carried out through a hydrothermal process at a temperature smaller than $300^{\circ} \mathrm{C}$ under alkaline conditions. The amount of 1-3 $\mathrm{M} \mathrm{NaOH}$ solution need an optimum condition to process the gel formation and zeolite crystallization. Of aluminum and silicon becamean aluminate $[\mathrm{Al}(\mathrm{OH}) 4]-$ and a silicate $[\mathrm{Si}(\mathrm{OH}) 4]$ which are very important in the zeolite formation process. Murat et al. (1992) has successfully synthesized zeolite A from the kaolin which has been calcined through 
hydrothermal treatment in an alkaline condition. Meanwhile, Shigemoto et al. (1993 and 1995) showed that the melting of fly ash and $\mathrm{NaOH}$ solution followed by a hydrothermal reaction at $100{ }^{\circ} \mathrm{C}$ produced zeolite $\mathrm{Na}-\mathrm{X}$. On the other hand, zeolite $\mathrm{Na}-\mathrm{A}$ produced by reaction fly ash and $\mathrm{NaOH}$ with added aluminium to the reactant. Zeolites are defined as crystalline alumina silica with a frame of three-dimensional arrangement formed from tetrahedral alumin. Silica which are interconnected through the use of shared oxygen atoms to form regular molecular dimensional cavities. In simple terms the zeolite structure can be imagined as the designation of honeycomb with cavities formed by tetrahedral of alumina and silica relationships (King, 1994).

Zeolites with their distinctive structure look interesting in physical and chemical properties. Some of the chemical properties of zeolite which are widely studied and utilized extensively are the nature of adsorption selectivity, ion exchangers and active catalysts. Zeolite from ash of rice husks can be used as a active catalyst in the conventer to increase its power so that it is known as a catalytic conventer.

\section{Experimental}

\subsection{Chemicals}

Al2O3, NaOH, Na2EDTAwere used directly. The pulp waste and ash of rice husks must be prepared before used.

\subsection{Rice Husk Ash Preparation}

The amount of 20 grams of rice husk ash mixed with $100 \mathrm{ml}$ of distilled water were stirred using a bar magnet for a few seconds. Then, the bar magnet was taken and the ash attached to the magnet was removed as a magnetic impurity. The process of disposal of magnetic impurity was repeated until the ash left behind. It was only non-magnetic rice husk ash which will be used as a materials to synthesize zeolite.

\subsection{Synthesis}

\subsubsection{Synthesis of Zeolite A}

Zeolite synthesis is carried out through a hydrothermal process as follows a total of $5 \mathrm{~g}$ of non-magnetic rice husk ash was mixed with $13.6 \mathrm{~g}$ of $\mathrm{NaOH}, 8.075 \mathrm{~g} \mathrm{of} \mathrm{Al}_{2} \mathrm{O}_{3}$ and $1.5 \mathrm{~g}$ of $\mathrm{Na}_{2}$ EDTA in distilled water up to a total volume of $100 \mathrm{~mL}$. The mixture was stirred on a hot plate with magnetic stirrer at $600 \mathrm{rpm}$ for 10 hours at room temperature. Then the mixture was refluxed for 3 hours at a temperature of $70^{\circ} \mathrm{C}$. The mixture was stored for a night at room temperature then refluxed again for 8 hours at $90-100^{\circ} \mathrm{C}$. Solid substances resulting from reflux are washed until got a neutral $\mathrm{pH}$ in the washing water.

\subsubsection{Synthesis of Zeolite $X$}

Zeolite synthesis was carried out through a hydrothermal process as follows a total of 5 grams of non-magnetic rice husk ash mixed with $12.66 \mathrm{~g}$ of NaOH, $6.21 \mathrm{~g}$ of $\mathrm{Al}_{2} \mathrm{O}_{3}$, and $1.5 \mathrm{~g}$ 
of $\mathrm{Na}_{2}$ EDTA in distilled water up to a total volume of $100 \mathrm{ml}$. The mixture was stirred on a hot plate with magnetic stirrer at $600 \mathrm{rpm}$ for 10 hours at room temperature. Then, the mixture was refluxed for 3 hours at a temperature of $70^{\circ} \mathrm{C}$. The mixture was stored for a night at room temperature then refluxed again for 8 hours at $110-120^{\circ} \mathrm{C}$. Solid substances resulting from reflux were carefully washed in the water until a neutral $\mathrm{pH}$ was achieved.

\subsection{Characterization}

\subsubsection{Infrared Spectroscopy}

Infrared spectroscopy is one of the easy and rapid methods to characterize the structure of zeolite. The fundamental vibrations of zeolite structure appear in the wave number area of $1500-300 \mathrm{Cm}^{-1}$ which is a medium infrared region. But in this study according to the available tools, measuring infrared spectroscopy was carried out in the wave number area $1500-400 \mathrm{Cm}^{-}$ 1 .

\subsubsection{Powder X-ray Diffraction}

Powder X-ray diffraction is an appropriate method for characterizing zeolites both qualitatively and quantitatively. Qualitative information for a zeolite can be achieved by the powder X-ray diffraction method. The fingerprint area diffract to gram zeolite can be estimated. It can be matched with a standard diffract to gram. The crystallinity and purity level of the zeolite synthesized and the characterization was carried out by X-ray diffraction at the area of diffraction angle (20): 4 - 40 degrees.

\subsubsection{Atomic Absorption Spectroscopy}

Atomic Absorption Spectroscopy is a quantitative elemental analysis method whose measurements are based on the absorption of light with a certain wavelength by a metal atom in a free state. The measurement of Al and Si levels used wavelengths $(\lambda) 309.3$ and $251.6 \mathrm{~nm}$ respectively.

\section{Results And Discussion}

\subsection{Non Magnetic Ash of Rice Husks}

Rice husk ash was obtained from burning rice husks at $600 \square \mathrm{C}$ for 4 hours. The ash produced from the burning of rice husks is shown in Table 1. 
Table 1. Ash produced by the burning of rice husks.

\begin{tabular}{|c|c|c|c|}
\hline Rice husks (g) & Rice husk ash (g) & Rice husk ash (\%) & Material lost (\%) \\
\hline 25.0 & 4.8 & 19.2 & 80.8 \\
\hline 25.0 & 4.9 & 19.6 & 80.4 \\
\hline 25.0 & 4.8 & 19.2 & 80.8 \\
\hline 25.0 & 4.7 & 18.8 & 81.2 \\
\hline
\end{tabular}

The ash produced from burning rice husks averaged around $19.2 \%$. This is in accordance with the results of Usman, et al (2014), the burning rice husks at a temperature of $500-900^{\circ} \mathrm{C}$ for 2 hours produced ash around $17.57-21.83 \%$. While the results achieved by Sapei, et al (2015) from burning rice husks at $750^{\circ} \mathrm{C}$ for 5 hours produced ash around $22.6 \%$. In the burning of rice husks, compounds such as cellulose, hemicellulose, and others contained in rice husks were converted to $\mathrm{CO}_{2}$ and $\mathrm{H}_{2} \mathrm{O}$ with ash remaining around 13.1-29.04\% (Houston, 1972). Furthermore, rice husk ash was treated with magnetic separation so that it obtained non magnetic rice husk ash which would be used as material for zeolite synthesis. The results of magnetic separation of rice husk ash are shown in Table 2. Magnetic separation successfully removed magnetic impurities from rice husk ash around 5.5-6.5\% so that non-magnetic rice husk ash was produced around 91-93\%.

Table 2. Results magnetic separation of rice husk ash.

\begin{tabular}{ccccc}
\hline \multirow{2}{*}{$\begin{array}{c}\text { Rice husk ash } \\
(\mathrm{g})\end{array}$} & \multicolumn{2}{c}{ Non magnetic ash of rice husks } & \multicolumn{2}{c}{ Magnetik impurity } \\
\cline { 2 - 5 } & $(\mathrm{g})$ & $(\%)$ & $(\mathrm{g})$ & $(\%)$ \\
\hline 20.0 & 18.6 & 93.0 & 1.1 & 5.5 \\
20.0 & 18.2 & 91.0 & 1.2 & 6.0 \\
20.0 & 18.2 & 91.0 & 1.3 & 6.5 \\
20.0 & 18.4 & 92.0 & 1.2 & 6.0 \\
\hline
\end{tabular}

Analysis of the chemical composition of non magnetic rice husk ash through spectrometry using X-ray fluorescence equipment produces spectra as shown in Figure 1.

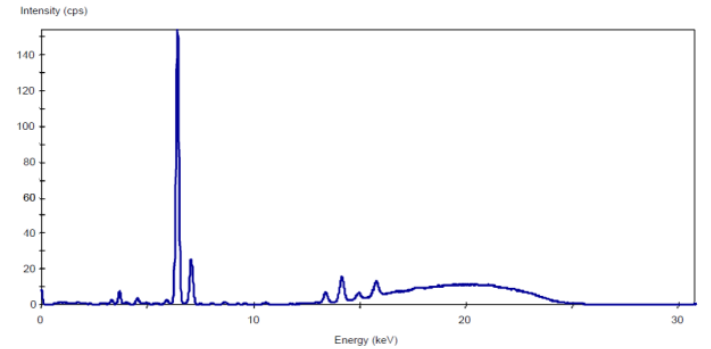

Fig. 1. Spectra results from the analysis of the chemical composition of non magnetic fly ash. 
Based on the peaks that appear can be identified the type and concentration of elements contained in the non-magnetic rice husk ash as shown in Table 3.

Table 3. chemical composition of non magnetic ricehusk ash

\begin{tabular}{ccc}
\hline Element & Concentration $(\mathrm{Wt} \%)$ & Intensity $(\mathrm{cps})$ \\
\hline $\mathrm{Mg}$ & 0.161 & 92.0 \\
$\mathrm{Al}$ & 2.083 & 661.0 \\
$\mathrm{Si}$ & 88.180 & 58679.0 \\
$\mathrm{P}$ & 0.922 & 208.0 \\
$\mathrm{~S}$ & 0.762 & 244.0 \\
$\mathrm{Ag}$ & 2.468 & 311.0 \\
\hline
\end{tabular}

The presence of $\mathrm{Si}$ elements in the non-magnetic rice husk ash as silica (SiO2) is evidenced from the results of the characterization of infrared spectroscopy and powder X-ray diffraction in Figures 2 and 3.

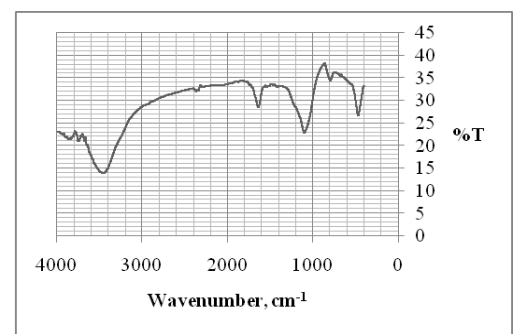

Fig. 2. Infrared spectra of non-magnetic rice husk ash

Infrared absorption bands in the wave number region 1101, 794, and $468 \mathrm{~cm}-1$ are characteristic silica absorption bands.

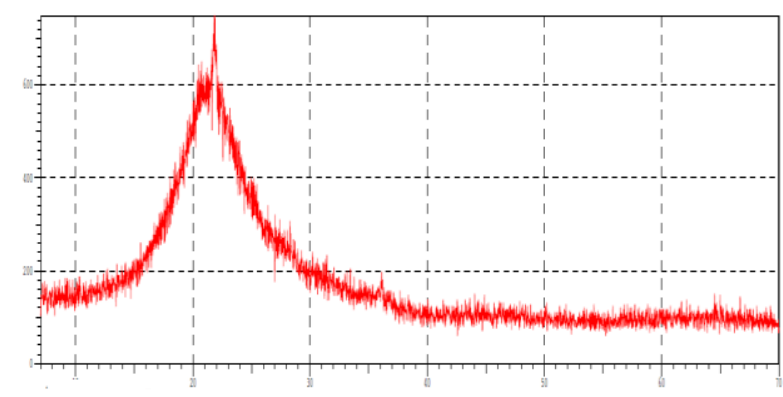

Fig. 3. Diffractogram of non-magnetic rice husk ash 
The diffraction peaks that appear at angles $\left(2 \theta^{\circ}\right)$ between $21-25^{\circ}$ indicate amorphous silica. Because of non-magnetic rice husk ash contains high levels of silica around $88.18 \%$, it is very suitable to be used as a material for zeolite synthesis.

\subsection{Zeolite A}

Zeolite $\mathrm{A}$ is produced from the hydrothermal process of a mixture of non-magnetic rice husk ash and alumina compound (A12O3) with a mole ratio of $\mathrm{Si} / \mathrm{Al}$ around 1.00 . Lowenstein's rule which rejects the existence of Al-O-Al bonds says that there is generally a mole ratio of $\mathrm{Si}$ to $\mathrm{Al}$ equal to 1in zeolite $\mathrm{A}$ but it is possible the ratio is higher or the mole ratio of $\mathrm{Si}$ to $\mathrm{Al}$ is greater than 1 (Dwyer and Dyer, 1994).In the mixture of non-magnetic rice husk ash and alumina compounds were added Na2EDTA compounds because in the nonmagnetic rice husk ash there were magnesium $(\mathrm{Mg})$ metal ions which could interfere the zeolite formation process. Catalfamo et al. (1994) found that materials with a calcium ion content of more than $3 \%$ by weight of material could not be converted into zeolites, due to the specific interaction between calcium ions and silicates which dissolved aluminasilica gel. The interaction of calcium ions with silicates can be suppressed as small as possible with the addition of EDTA, which can selectively form complexes with calcium ions. Magnesium ions have properties similar to calcium ions which can interfere the zeolite formation.

Furthermore, the synthesized zeolite from non-magnetic rice husk ash was characterized by infrared spectroscopy shown in Figure 4. The absorption band that appears in the wavenumber region of $443.2 \mathrm{~cm}-1$ marks the buckling vibration of the T-O bond from the tetrahedral TO4 ( $\mathrm{T}$ is $\mathrm{Si}$ or $\mathrm{Al}$ ). While the strong absorption band that appears at $1000 \mathrm{~cm}$. its asymmetric stretching vibration. These two types of vibrations are TO4's internal tetrahedral vibrations. Whereas the external vibration between the tetrahedral junction of TO4 is shown in the absorption bands which appear at 603.2 and $678.2 \mathrm{~cm}-1$ which indicate the double ring vibration. The absorption bands contained in this spectrogram are the characteristics of zeolite A because the infrared spectogram with absorption bands that appear in 4 wave number regions $1250-950,650-500,500-420$ and 400-300 cm-1 are typical infrared spectograms of zeolite A. Of the four typical infrared absorption bands of the zeolite, there are two absorption bands at $1250-950$ and $500-420 \mathrm{~cm}-1$ are generally applicable to all zeolites, while the absorption band at $650-500 \mathrm{~cm}-1$ is a typical absorption of zeolite A which marks vibrations of double 4 ring (Flanigen et al, 1971).

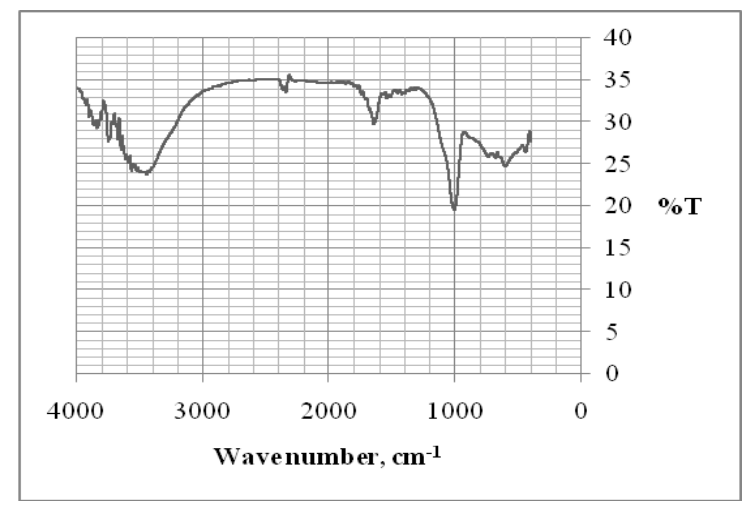

Fig. 4. The infrared spectrogram of synthesized zeolite A from non-magnetic rice husk ash 
To determine the purity and crystallinity degree of synthesized zeolite A, were characterized by powder X-ray diffraction at diffraction angle (2 $\square$ ): 0-50 $\square$ as shown in Figure 5 .

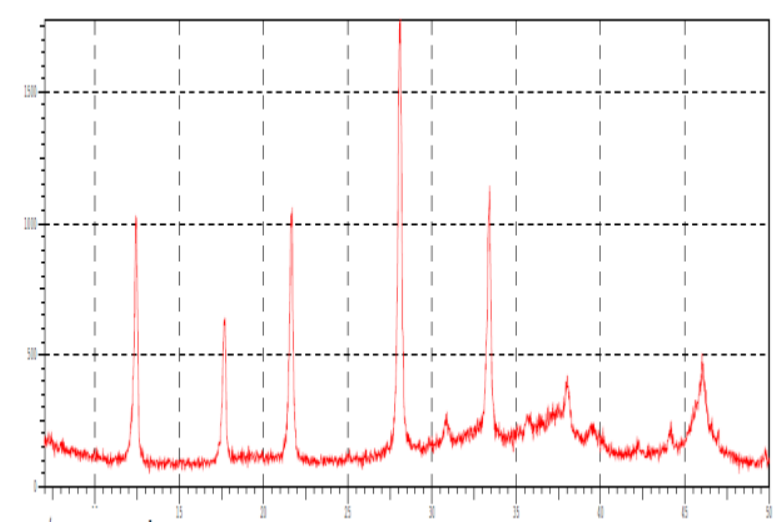

Fig. 5. Diffractrogram of synthesized zeolite A from non-magnetic rice husk ash

The peaks diffraction which indicated the presence of A zeolite were shown at the diffraction angle $(2 \theta): 12.42,17.65,21.36,28.07,30.81$ and 33.35 . The six diffraction peaks correspond to the main peaks of zeolite A. Imbert et al. (1994) which revealed that the crystallinity of zeolite A synthesized was determined by the total intensity of the 10 main peaks at $\mathrm{d}$ : $2.626,2.987,3.278,3.407,3.714,4.107,5.510,7.110,8.750$ and 12.290 which correspond to the diffraction angle value: $34.1,30.0,27.2,26.2,24.0,21.6,16.1,12.4,10.1$ and $7.2^{\circ}$. Based on the number of typical zeolite A main peaks that compared to the number of typical zeolite A main peaks which resulted by Imbert et al. It can be estimated that zeolite A produced from non-magnetic rice husk ash has a level of crystallinity around $60 \%$. However, thesolid zeolite can be estimated to have a high purity levels which are indicated by the absence of diffraction peaks of other minerals. The diffraction peaks have high intensity and sharp.

Based on the results of Atomic Absorption Spectroscopy measurements at wavelengths of 309.3 and $251.6 \mathrm{~nm}, \mathrm{Si}$ and $\mathrm{Al}$ levels in synthetic zeolite A were calculated about 16.5 and $14.8 \%$ respectively.Thus, the $\mathrm{Si}$ to $\mathrm{Al}$ mole ratio in zeolite $\mathrm{A}$ from non magnetic rice husk ash is around 1.075 or 1,1. This is in accordance with Lowenstein's rules (Dwyer and Dyer, 1994).

\subsection{Zeolite X}

Zeolite $\mathrm{X}$ is produced from the hydrothermal process of a mixture of non-magnetic rice husk ash and alumina compound (A12O3) with a mole ratio of $\mathrm{Si} / \mathrm{Al}$ around 1.30.The synthesized zeolite from non magnetic rice husk ash was characterized by infrared spectroscopy in the area $(300-1500) \mathrm{cm}-1$ to identify the fundamental tetrahedral vibration of TO4 (T is Si or Al) which are the building units of the zeolite X structure. The fundamental vibration of zeolite structures in the medium infrared region can be classified in 2 classes of vibration, namely internal vibrations and external vibrations. The vibrational frequency observed for tetrahedral TO4 does not distinguish between tetrahedral silica and alumina, but it's the mean frequency of the tetrahedral vibrations.Moreover, all peaks caused by internal 
vibrations are very sensitive to composition in the structure of the zeolite framework. For example, the increase in Si content causes the absorption peak in the $568 \mathrm{~cm}-1$ wave number area to shift towards the higher wave area (Hamdan, 1992).

Infrared spectra show absorption bands in four wave number regions 440-540, 500-650, $750-820$ and 1000-1120 cm-1 which mark the typical structure of zeolite X. The presence of a strong absorption band at a wave number of $1007 \mathrm{~cm}-1$ marks the vibrational range internal asymmetry of $\mathrm{O}-\mathrm{Si}-\mathrm{O}$ or $\mathrm{O}-\mathrm{Al}-\mathrm{O}$ of TO4 (Wang et al. 2013 and Bahri et al., 2015) while the absorption band at $745 \mathrm{~cm}-1$ marks the vibration of the external symmetry range of $\mathrm{O}-\mathrm{Si}$ $\mathrm{O}$ or O-Al-O (Socrates, 1994). Meanwhile the absorption band at $440 \mathrm{~cm}-1$ shows the bending vibration of $\mathrm{O}-\mathrm{Si}-\mathrm{O}$ or $\mathrm{O}-\mathrm{Al}-\mathrm{O}$. As for the six double ring vibration (D6R) which is characteristic of the zeolite $\mathrm{X}$ is shown by the infrared absorption band at wave number 606.1 $\mathrm{cm}-1$.

Furthermore, the synthesized zeolite $\mathrm{X}$ was characterized using powder $\mathrm{X}$-ray diffraction to determine its purity and crystallinity. The diffractogram is shown in Figure 6.

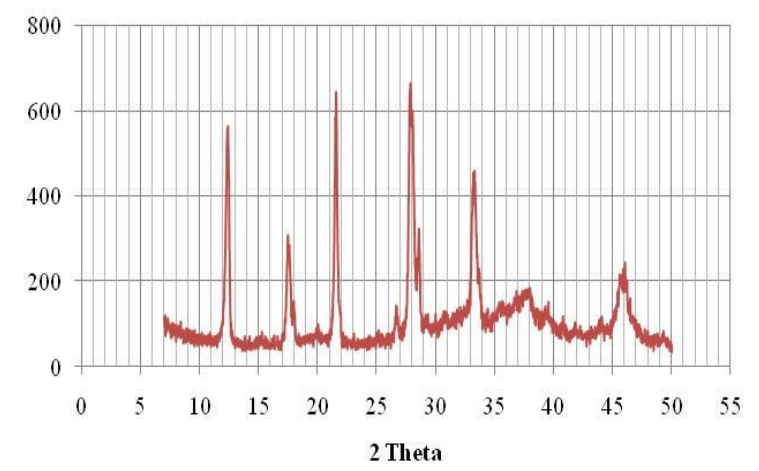

Fig. 6. Diffractogram of zeolite $X$ as a result of synthesis from non magnetic rice husk ash

The peaks diffraction which indicate the presence of $X$ zeolite were shown at the diffraction angle $(2 \theta): 12.34,17.51,21.53,27.9,28.5$ and 33.22 . The six diffraction peaks correspond to the main peaks of zeolite X. Von Balmoos (1984) suggested that the crystal structure of zeolite $X$ as shown by diffraction peaks at the following angles $(2 \theta): 6.12 ; 10.00$, $11.73,15.43,18.42,20.07,22.47,23.31,26.65,29.21,30.30,30.94,31.98,33.59,34.18$ and $37.34^{\circ}$. Among these diffraction peaks, the peak that appears at an angle $(2 \theta): 6.12,10.00$, $11.73,15.43,23.31,26.65,30.94,31.98$ and $33.59^{\circ}$ are the main typical peaks of zeolite $\mathrm{X}$ which have relatively higher intensity than other peaks. X-zeolite synthesized from nonmagnetic rice husk ash has six peaks which correspond to the typical peak of zeolite $\mathrm{X}$ according to Balmoos with the highest intensity at the diffraction peak of 27.9. This means that the zeolite synthesized by crystallinity is around $66.7 \%$. But these zeolite solids can be estimated to have high purity levels which are indicated by the absence of diffraction peaks of other minerals and the diffraction peaks that appear to have high intenstity and sharp.

Based on the results of AAS measurements at wavelengths of 309.3 and $251.6 \mathrm{~nm}$, Si and Al levels in synthetic zeolite A were calculated about 16.34 and $12,7 \%$ respectively.Thus it can be determined that the $\mathrm{Si}$ to $\mathrm{Al}$ mole ratio in zeolite $\mathrm{X}$ from non magnetic rice husk ash is around 1.23 . 


\section{Conclusions}

The burning of rice husk produce ash around $19.2 \%$ and the magnetic separation results non-magnetic ash of rice husk around $91-93 \%$.

The non magnetic ash of rice husk content $\mathrm{SiO}_{2}$ around $88.18 \%$ so it can be used as material for synthesis of zeolite .

A and X zeolites produced from non magnetic ash of rice husk have a level of crystallinity around 60 and $66.7 \%$ respectively.

Acknowledgements. Thank you to the Medan State University Research Institute for funding this research through the Expertise Lecturers Group research scheme. Appreciation is expressed to Rizky Kurniawan and Essy Risa Pradina Perangin-angin who had helped the implementation of this research.

\section{References}

[1] Catalfamo, P., Patane, G., Prmerano, P., Di Pasquele, S., and Corigliano, F..: "The Presence of Calsium in The Hydrothermal Conversion of Amorphous Aluminosilicates in Zeolite: Interference and Removal", Mateial Engineering, 5, 2, 159 - 173 (1994)

[2] Dwyer, J. and Dyer, A.: "Zeolite fro Industry", Chemistry and Industry, 2, 258 - 268. (1994)

[3] Flanigen, E.M., Khatami, H., and Szimanski, H.Al.: "Infrared Structure Studies of Zeolite Framework, Molecular Sieve Zeolite-I”, American Society Advances in Chemistry, 101, 201 229. (1971)

[4] Hamdan, H.: Introduction to Zeolite: Synthesis, Characterization and Modification, University Technology Malaysia (1992)

[5] Houston, D.F.: Rice Chemistry and Technology, American Assosiaciton of Cereal Ceramic, Inc., Minnecosta. (1972)

[6] King, R.B.: , Enclycopedia of Inorganic Chemistry, 8, John Wiley \& Sons, Singapore (1994)

[7] Murat, M., Amokrane, A., Bastide, J.P., and Montanaro, L.: Synthesis of Zeolite From Thermally Actived Kaolinite, Some Observation on Nucleation and Growth, Clay Mineral, 27, 119 - 130. (1992)

[8] Sapei, L., Padmawijaya, K.S., Sutejo, A dan Theresia, L.: Karakterisasi Silika Sekam Padi dengan Variasi Temperatur Leaching Menggunakan Asam Asetat, Jurnal Teknik Kimia, 9 (2): 38 - 43 (2015)

[9] Shigemoto, N., Hayashi, H., and Miyaura, K.: "Selective Formation of Na-X Zeolite From Coal Fly Ash by Fusion with Sodium Hydroxide Prior to Hydrothermal Reaction”,Journal of Materials Science, 28, 4781 - 4786. (1993)

[10] Shigemoto, N., Sugiyama, S., Hayashi, H., Miyaura, K..: "Characterization of Na-X, Na-A and Coal Fly Ash Zeolites and Their Amorphous Precursors by IR, MAS-NMR and XPS", Journal of Materials Science, 30, 5777 - 5781 (1995)

[11] Usman, A.M., Raji, A., and Waziri, N.H.: Characterization of Girel Rice Husk Ash for Silica Potential, IOSR Journal of Environmental Science, Toxicology and Food Technologi, 8 (1) : 68 - 71 (2014)

[12] Von Ballmoos, R.: Collection of Simulated XRD Powder Patterns for Zeolites, Mobil Research and Development Corporation, Princenton, USA (1984) 